\section{MORPHINE DECREASES IN VIVO CATECHOL ACTIVITY IN THE ROSTRAL VENTROLATERAL MEDULLA}

Louie Wang MD, Murray Hong MSc, Brian Milne MD, Khem Jhamandas PhD.

Department of Pharmacology and Toxicology and Department of Anaesthesia, Queen's University, Kingston, Ontario K7L 3N6

INTRODUCTION: Opiates are hypothesized to cause a vasodepressor effect by acting on the rostral ventrolateral medulla (RVLM) wherein lie neurons which control sympathetic tone. Using voltammetry which measures catecholamine oxidation currents $(\mathrm{CA} \cdot \mathrm{OC})$ generated by adrenergic activity in these neurons, our objective was to demonstrate the in vivo effect of morphine on the RVLM.

METHODS: Halothane anaesthetized rats were implanted stereotaxically with carbon-fibre electrodes to monitor CA.OC by differential normal pulse voltammetry. Mean arterial pressure (MAP) was monitored by a femoral arteria line. After stabilization, rats received either intracerebroventricular (icv) morphine $10 \mu \mathrm{g}(n=5)$ followed 45 minutes later by intravenous (iv) naloxone $1 \mathrm{mg} \cdot \mathrm{kg}^{-1}$ or icv saline $5 \mu l(n=5)$ followed by iv saline $0.45 \mathrm{ml}$. Changes in MAP and CA.OC were compared to baseline.

RESULTS: The CA.OC was maximally depressed by 39 percent 45 minutes following morphine (Fig 1). Naloxone reversed the effects of morphine and produced a significant 21 percent rebound increase in the CA.OC. MAP was maximally depressed by 21 percent 45 minutes following morphine (Fig 1). This decrease in MAP was reversed by naloxone. Saline treatment had no significant effect on the CA.OC (ANOVA, $p=0.321$ ) or MAP (ANOVA, $p=.531$ ).

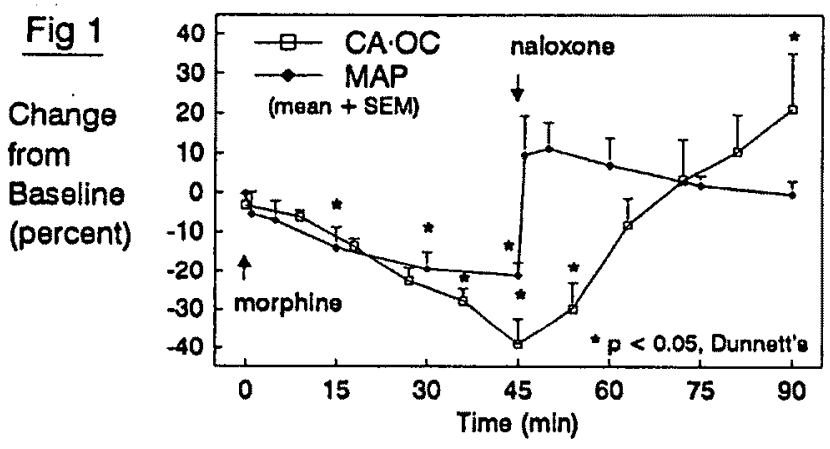

DISCUSSION: An increase in the CA.OC in the RVLM accompanies induced hypotension possibly by way of a baroreceptor reflex. However, our results suggest that morphine depresses adrenergic neurons in the RVLM to produce a vasodepressor effect. The rebound effect following the antagonism of morphine with iv naloxone is analogous to the observation of excessive sympathetic activity in post-operative patients receiving naloxone. This acute opiate withdrawal phenomenon is possibly mediated through the RVLM and if so, it may be prevented by attenuation of activity in this area.
CAN BEDSIDE RECR BXTENSION PREDICT DIFFICULT INTUBATION?

Frances L. Chow MD, Peter G. Duncan FRCPC, William E. Code FRCPC, Ray w. Yip FRCPC

Department of Anaesthesia, Royal University Hospital, Saskatoon, Saskatchewan, S7N OXO

INTRODUCTION

Preoperative airway examination includes assessment of necessary neck extension to approximate mouth and trachea axes which facilitates direct glottic exposure. While neck extension is considered the olngle beat discriminating variable between an easy and a difficult alrway, reduced neck extension can only be diagnosed by radiographs. In Mallampat 1's airway classification study of 210 patients, 78 of difficult intubations were missed, it is posible that neck extension evaluation would have enhanced that neck extension evaluation would have enhanced the hypothesis, that decreased neck extension is a rellable predictor of difflcult intubation.

METHODS - Case Control study

Thirty "difficult intubation" patients were matched post-laryngoscopy for age, sex, disease with 30 "easy intubation" patiente. Ail 60 patients were given a Mallampati alrway classiflcation by an observer blinded to their laryngoscopy grading. Dlstance measurements between mandibular tip to sternal notch in the neutral and extension neck positions were done with a tape measure; the difference was calculated. Neck radiographs were taken in similar positions; superimposition of the extension on neutral radiograph using $C 5$ alignment allowed neck extension angles to be meagured with a protractor.

Rasuress

Statistical analysis of elinical to radiographic neck extension was done using Chi square and Pearson's correlation coefficient.

TABLE Is Corxelation of Extension Distance with Intubation Difficult

\begin{tabular}{|l|c|c|}
\hline & Difficult & Control \\
\hline $\begin{array}{l}\text { Ext. - Neutral Distance } \\
\text { Mean } \pm \text { SD (Range) }\end{array}$ & $\begin{array}{c}3.5 \pm 0.8 \mathrm{~cm} \\
(2-5 \mathrm{~cm})\end{array}$ & $\begin{array}{l}6.0 \pm 1.4 \mathrm{~cm} \\
(4-10 \mathrm{~cm})\end{array}$ \\
\hline $\begin{array}{l}\text { fof Patients with }<5 \\
\text { cm Neck Exteng1on }\end{array}$ & 27 & 2 \\
\hline
\end{tabular}

Very good correlation existed between ext.-neutra distance and radiographic ext. angle, $(x=0.81)$. Using neck extension $<5 \mathrm{~cm}$ as a predictor of difficult intubation, sensitivity was 908 . apecificity 938, positive predictive value 938, negative predictive value $908, \operatorname{chl}$ square value 0.001 .

DISCUSSION

Normative clinical data for neck extension has not been published. In this study $27 / 30$ patients with difficult intubation and $2 / 30$ controls had $<5 \mathrm{~cm}$ of neck extension. Little correlation existed between Mallampat 1 intraoral classification and lasyngoscopy findings of grades II and III if evaluation of neck extension was excluded.

CONCLUSION

Decreased neck extension assessed at the bedside is a predictor of unanticipated difflcult intubation. Neck extensions of $<5 \mathrm{~cm}$, in conjunction with the Mallampati airway classification, should become a routine part of airway assessment.

REFERENCES :

1. Bellhouse CP, Dore C. Anesth Intens Care, 1988, 16: $329-37$

2. Mallampati SR, Gugino Laverne. Can Anaesth Soc J. $1985 / 32$ : 4/PP. $429-34$. 